\title{
Moral Masochism: On the Connection Between Guilt and Self-Punishment
}

AQ: au

\author{
David A. Pizarro and Thomas Gilovich \\ Cornell University
}

\author{
Yoel Inbar \\ Tilburg University
}

Dan Ariely

Duke University

\begin{abstract}
Do people sometimes seek to atone for their transgressions by harming themselves physically? The current results suggest that they do. People who wrote about a past guilt-inducing event inflicted more intense electric shocks on themselves than did those who wrote about feeling sad or about a neutral event. Moreover, the stronger the shocks that guilty participants administered to themselves, the more their feelings of guilt were alleviated. We discuss how this method of atonement relates to other methods examined in previous research.
\end{abstract}

Keywords: guilt, self-punishment, morality

Even if it was in an indirect and abnormal way, the guilty man had been punished; balance had been reestablished. The cut could now close.

- Michel Houellebecq, 2011, p. 267

From the very beginning of Western thought, justice has been tied to the idea of "balance." Writing in the 6th century B.C., the Greek philosopher Anaximander likened justice to the cycle of the seasons. Just as the cold and wet of winter is balanced by the heat and drought of summer, justice requires that violations be balanced by retribution. Nussbaum (1993, p. 89) describes this "primitive sense of the just" as the belief that "for encroachment and pain inflicted a compensating pain and encroachment must be performed." The view that transgressions must be balanced by pain inflicted on the transgressor has remained a major tenet of Western moral thought—indeed, the belief is strong enough that people may sometimes inflict pain on themselves in order to balance their misdeeds (Bloom, 2010). Medieval European flagellants, for example, wandered en masse from town to town, publicly beating themselves to atone for their sins (Leff, 1999). More recently, Sigmund Freud claimed that repressed feelings of guilt lead to a need for suffering - a phenomenon he called "moral masochism" (Freud, 1924/1953).

Yoel Inbar, Department of Social Psychology and Tilburg Institute for Behavioral Economics Research (TIBER), Tilburg University; David A. Pizarro and Thomas Gilovich, Department of Psychology, Cornell University; Dan Ariely, Department of Fuqua School of Business \& The Center for Cognitive Neuroscience, Duke University.

This research was supported by National Science Foundation Grant SES-0922323. We thank Al Herrera for his help with data collection, Lieke van Duist and Arnoud Plantinga for their help coding participants' responses, and Matt Nock and the Tilburg HARDCORE lab group for helpful comments on drafts of the manuscript.

Correspondence concerning this article should be addressed to Yoel Inbar, Department of Social Psychology and Tilburg Institute for Behavioral Economics Research (TIBER), Tilburg University, P.O. Box 90153, 5000 LE Tilburg, The Netherlands. E-mail: yinbar@uvt.nl
The idea that people seek suffering to reduce feelings of guilt may seem implausible — why would choosing to feel worse in one respect help one feel better in another? In their influential review of the empirical literature on guilt, Baumeister, Stillwell, and Heatherton (1994) echoed this skepticism, concluding that "empirical work has largely failed to demonstrate that guilty people wish to suffer or be punished" (p. 256). However, more recent research appears to support a link between guilt and self-harm. Participants who were led to believe that their insufficient effort had financially harmed an interaction partner later imposed financial sanctions on themselves (Nelissen \& Zeelenberg, 2009, Study 2), and participants submerged their hands longer in painfully cold water after recalling an occasion when they had ostracized another (Bastian, Jetten, \& Fasoli, 2011).

Although these results suggest a link between guilt and selfinflicted suffering, they do not necessarily support the claim that guilt in particular motivates self-punishment. That is, neither Bastian et al. (2011) nor Nelissen \& Zeelenberg (2009, Study 1) induced any negative emotion other than guilt. This leaves open the possibility that other negative emotions might also lead to self-punishment, perhaps due to a general motivation to distract oneself from negative emotional states rather than an effort to relieve the feeling of guilt in particular. Our first aim in the current research, therefore, was to test whether guilt, specifically, motivates self-punishment. To do so, we asked participants to recall an experience that made them feel guilty, an experience that made them feel sad, or a neutral event. We predicted that those who wrote about a guilt-inducing event would subsequently inflict stronger electric shocks on themselves than those in the neutral or negative-emotion control groups.

This design also offers two other improvements on existing work. First, the research described above focused on reactions to the specific infractions of ostracizing others (Bastian et al., 2011) or making an insufficient effort on behalf of another (Nelissen \& Zeelenberg, 2009). Here, by asking people to recall a past guilt-inducing event, we sample a wider range of naturally occurring elicitors of guilt. Second, by examining people's 
willingness to give themselves electric shocks rather than immersing their hands in cold water, we rule out a possible confound: While holding one's hand in cold water causes physical pain, it might also be construed as cleansing, which has also been shown to be motivated by feelings of guilt (Zhong \& Liljenquist, 2006).

\section{Method}

Forty-six undergraduate participants ( 25 female) were recruited to participate in "a study of negative life events" and were randomly assigned to the guilty $(n=17)$, sad $(n=14)$, or neutral control $(n=15)$ conditions. They were greeted by the experimenter, taken to a private room, and told that the first part of the study would entail writing about a negative or neutral event from their past. The experimenter handed participants an envelope and told them that it contained the instructions for this part of the study. When participants had finished, they were told to put the completed materials in the envelope, seal it, and notify the experimenter, who would be waiting outside. In the envelope, participants found a prompt asking them to describe the time that they felt "most guilty," "most sad," or the last time they went grocery shopping. Following the writing task, participants in the guilt and sadness conditions were asked to rate (on 10-point scales anchored by Not at all guilty [sad] and Extremely guilty [sad]) how much they felt the emotion in question - both at the time of the event and when thinking about the event now. In order to bolster the cover story and minimize suspicion, participants rated only the emotion about which they had just written (control participants rated no emotions).

When participants had finished, the experimenter collected the sealed envelopes and told them that they would now experience "a negative event in the lab"-namely, they would receive six electric shocks from a shock apparatus (a Grass Technologies SD-9 Stimulator designed for human-subjects use). The experimenter attached two electrodes to the inside of the participant's left or right wrist and administered a $30 \mathrm{~V}$ shock (a voltage that is detectable but not painful). On subsequent trials, participants could choose the intensity of the shocks themselves. However, in order to ensure that participants did not give themselves excessively strong shocks, their ability to increase the voltage was restricted. On each trial, they were given the option to increase the intensity of the shock by $10 \mathrm{~V}$ (they could also decrease it by $10 \mathrm{~V}$ or leave it unchanged). Thus, the maximum possible voltage on Trial 6 was 80V. (Pretesting on six of the first author's colleagues showed that on average shocks began to feel unpleasant at 56V.) Following the shock task, participants completed the 20-item Positive and Negative Affect Schedule (PANAS; Watson, Clark, \& Tellegen, 1988), which includes the item guilty. Finally, participants were probed for suspicion using a multistep procedure: They were first asked whether they had noticed anything "strange, confusing, or suspicious" about the study, and then asked directly whether they thought the writing and shock tasks were related. Participants who expressed suspicion during either of these steps were asked to elaborate by the experimenter. Following the suspicion check, the true purpose of the study was explained and participants were thanked and dismissed.

\section{Results}

Five participants (four in the guilt condition and one in the neutral condition) guessed our hypothesis ${ }^{1}$ and were removed from Fn1 subsequent analyses, leaving 41 participants in the study. An examination of the emotion ratings showed that the emotion inductions were successful. Participants in the guilt condition reported feeling very guilty at the time of the event $(M=8.85, S D=$ $2.15)$ and rather guilty currently $(M=5.69, S D=2.60)$; participants in the sadness condition reported feeling very sad at the time of the event $(M=9.07, S D=1.21)$ and rather sad currently $(M=$ $5.0, S D=3.0) .^{2}$ Participants in the guilt condition wrote about a Fn2 wide variety of elicitors, including emotionally or physically harming others $(n=3)$, disappointing family members $(n=3)$, lying or cheating $(n=3)$, sexual infidelity $(n=2)$, and feeling personally responsible for someone's death $(n=2)$.

We examined shock voltages from Trials 2-6 (i.e., the trials for which the voltage was not fixed). Preliminary analyses showed that the mean shock voltage across these trials was higher for women than for men, so we included gender as a covariate in the following analysis. In order to examine whether the guilt induction caused an increase in self-administered shock, voltages from Trials 2-6 were subjected to a repeated-measures analysis of variance with condition and gender as between-subjects factors. This analysis revealed the expected main effect of condition, $F(2,37)=$ $3.29, p=.05$, partial $\eta^{2}=.13$. Participants in the guilt condition gave themselves stronger shocks $(M=53.5 \mathrm{~V}, S D=9.8)$ than did those in the sadness condition $(M=43.7 \mathrm{~V}, S D=14.9)$ or the neutral condition, $(M=43.1 \mathrm{~V}, S D=17.2$; see Figure 1$)$. F1 Follow-up contrasts showed that the mean voltage in the guilt condition differed significantly from both the neutral condition, $F(1,37)=5.81, p=.02, d=.38$, and the sadness condition, $F(1$, $37)=3.98, p=.05, d=.31$. The neutral and sadness conditions did not differ significantly from each other, $F(1,37)=.20, n s$. Also, consistent with the preliminary analysis, women gave themselves significantly stronger shocks than men did, $F(1,37)=7.49$, $p=.01$.

\footnotetext{
${ }^{1}$ Participants were debriefed using a standard funnel procedure in which they were asked: 1) whether they had noticed anything "strange, confusing, or suspicious" during the study; 2) whether they thought the different tasks were related; 3 ) if so, how they were related. We excluded participants who said they thought the emotion produced by the writing task was intended to affect whether or how much they were willing to shock themselves. We did not exclude participants who thought that there was some general (unspecified) connection between the tasks, who thought the writing task was meant to affect their emotional state, or who guessed, after prompting from the experimenter, that we might be interested in how mood affected pain perception. (Excluding the two participants-both in the sadness condition-who gave this response did not affect pattern or significance of the results).

${ }^{2}$ To further verify that participants had recalled guilt- and sadnessevoking experiences, we also asked two coders to read the descriptions written by participants in the guilt and sadness conditions and rate- on a scale from 1 (Not at All) to 7 (Very Much)— how much they thought the writer had felt guilt, sadness, anger, disgust, and fear. The two coders' ratings were correlated significantly for each emotion ( $r$ s from .40 to .73) and were therefore averaged. As expected, writers were rated as feeling more guilt in the guilt condition $(M=6.04, S D=.69)$ than in the sadness condition $(M=2.75, S D=2.05), t(25)=5.26, p<.001$; and as feeling more sadness in the sadness condition $(M=5.79, S D=1.12)$ than the guilt condition $(M=3.77, S D=1.41), t(25)=4.13, p<.001$. There were no significant differences for the other three emotions, all $p \mathrm{~s}>.19$.
} 


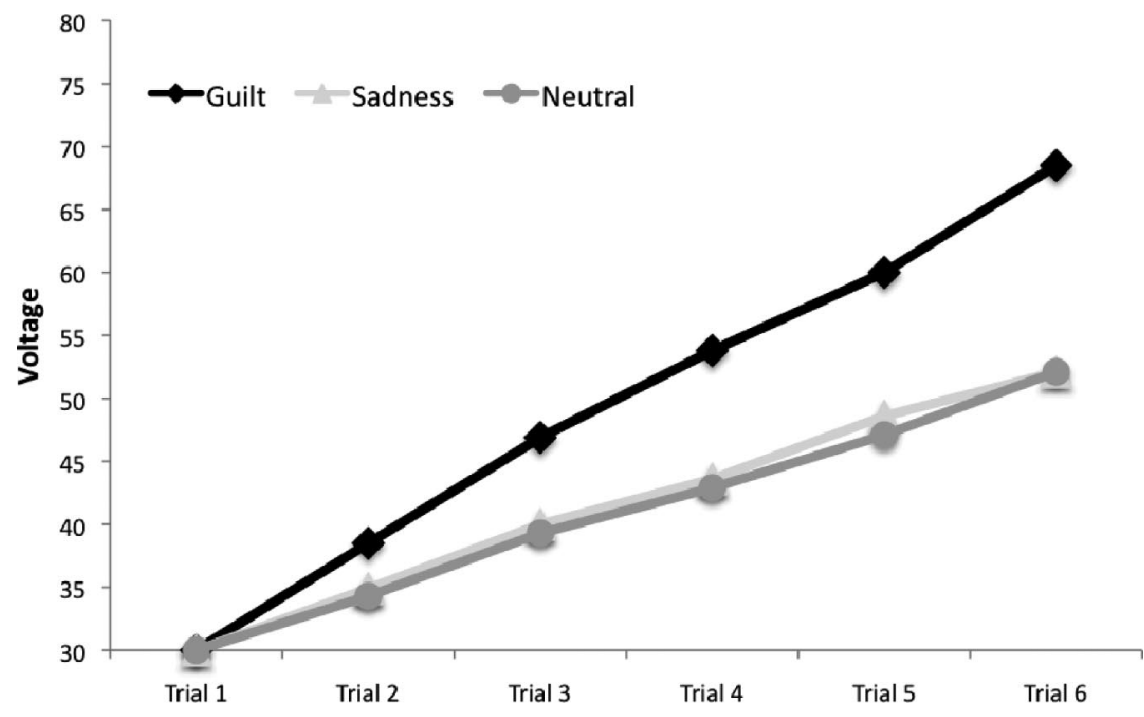

Figure 1. Mean shock voltage per trial by condition.

We next examined whether participants' ratings of guilt preceding the shock task (which were obtained only from those in the guilt condition) were correlated with the intensity of the shock on each trial-that is, whether participants who felt guiltier gave themselves stronger shocks. As our account would predict, all five correlations were positive, with $r$ s ranging from .10 to .40 . However, due to the low number of observations $(n=13)$, no individual correlation was statistically significant. Next, we tested whether shock intensity correlated with the decline in guilt from Time 1 (immediately after the writing task) to Time 2 (when subjects completed the PANAS following the shock task). We rescaled the Time 1 guilt ratings (which were on a 10-point scale) to match the 5-point scale of the PANAS, and subtracted guilt ratings at Time 1 from those at Time 2. Thus, negative numbers on this measure indicate a decline in guilt from Time 1 to Time 2. Indeed, decline in guilt correlated with average shock intensity across Trials 2-6, $r(13)=-.57, p=.04$ : The stronger the shocks participants gave themselves, the more their feelings of guilt were alleviated.

\section{Supplementary Sample}

One potential limitation of these findings is that after excluding suspicious participants, the sample size in the guilt condition was low $(n=13)$. In order to ensure the reliability of our results, we subsequently ran an additional 27 participants (14 in the guilt condition-of which three were excluded due to suspicion-and 13 the neutral condition). ${ }^{3}$ To establish that the data from these participants could safely be combined with our earlier data, we compared shock voltages from participants in the guilty and neutral conditions to those from our initial data collection, checking for a main effect of sample or a sample $\times$ condition interaction. Neither was significant $\left(F_{\mathrm{S}}<1\right)$. We therefore combined the samples and, again, subjected voltages from Trials 2-6 to a repeated-measures analysis of variance with condition and gender as between-subjects factors. This analysis again showed a main effect of condition, $F(2,61)=4.27, p=.03$ : Participants in the guilt condition gave themselves more powerful shocks $(M=$ $52.9 \mathrm{~V}, S D=10.9)$ than did those in the sadness condition $(M=$ $43.7 \mathrm{~V}, S D=14.9)$ and the neutral condition $(M=43.6 \mathrm{~V}, S D=$ 15.8). Thus, it does not appear that the differences reported above are a false positive result caused by too few participants in the guilt condition.

\section{Discussion}

Recalling a guilt-inducing event made participants more willing to inflict unpleasant electric shocks on themselves. This effect cannot be attributed merely to the fact that guilt is a negative emotion, as participants who recalled a sadness-inducing event gave themselves shocks that were significantly less intense than participants in the guilt-induction group, and that did not differ in intensity from those of participants in the neutral control group. These results also provide evidence that experiencing guilt resulting from a range of real-life guilt-inducing events can give rise to "moral masochism"-it is not limited to any idiosyncratic feature of the specific manipulations used to induce guilt in previous studies. Finally, our results address a potential confound in previous research demonstrating a link between guilt and self-inflicted pain using a cold-pressor task. By using self-inflicted shocks, we avoided the possibility that participants construed the masochistic behavior as "washing away" the taint of bad behavior.

Our findings lend support to the proposition that feeling guilty about one's own moral transgressions can lead people to engage in physical self-punishment, and that such self-punishment, in turn, serves to reduce feelings of guilt. These findings may be relevant to the substantial clinical literature on nonsuicidal self-injury (NSSI), which often manifests as cutting, burning, or inserting objects under the skin (Nock \& Prinstein, 2005). Episodes of self-injury are often interpreted as attempts to distract oneself from

\footnotetext{
${ }^{3}$ In an effort to reduce suspicion, we asked participants to write about a time they had done something unethical (see Zhong \& Liljenquist, 2006), rather than the time they felt "most guilty."
} 
one's unpleasant emotional state (Nock \& Prinstein, 2004), but note that this is unlikely to be the case for the results reported here. Sadness is an unpleasant emotion as well, of course, and participants would presumably be motivated to take their minds off their sadness as well as their guilt. However, Nock, Prinstein, and Sterba (2009), using real-time experience sampling, found that self-injury episodes were often preceded by thoughts of "anger at oneself" and "self-hatred." Although such cognitions are not uniquely associated with guilt (for example, they are also common to the experience of shame; Tangney \& Dearing, 2002), it may be useful for future research to examine the connections between NSSI and the phenomena we have documented here. Is NSSI fueled exclusively by a quest for distraction from unpleasant emotions in general, or might guilt play a special role in the same way it did in our nonclinical sample?

Another important question is the extent to which people explicitly use pain to balance out misdeeds. There is some evidence that under certain circumstances people might do so-for example, Nelissen (2012) found that participants who believed that they had exerted insufficient effort on behalf of another person later agreed to receive more intense shocks, but only when the other person was present. Nelissen argued that in this case, self-inflicted punishment served as a signal of remorse to one's victim. And, of course, religious flagellants believed that their self-inflicted pain signaled their remorse to God (Leff, 1999). In the current study, however, most participants did not explicitly acknowledge a relationship between their guilty feelings and the shock task. How, then, are we to explain their behavior? We believe that in this case (as in many others; see Nisbett \& Wilson, 1977), behavior was driven by an intuitive process of which participants had little or no introspective awareness. Such intuitively driven moral judgments are quite common. For example, people make harsher moral judgments in a messy room or when there is a foul smell in the air, while remaining completely unaware of these influences (Schnall, Haidt, Clore, \& Jordan, 2008). Similarly, in the current case we believe that self-punishing to restore balance was motivated by an intuitive link between transgression and punishment that participants could not or would not articulate.

Of course, a motivation to balance the scales need not lead to self-destructive behavior, and ideally it might lead to other-serving behavior instead (or perhaps in addition). A sizable experimental literature indicates that people often deal with their guilt over a bad deed by doing a good deed for someone else or for society in general (Carlsmith \& Gross, 1969; Darlington \& Macker, 1966; O'Keefe \& Figge, 1997; Regan, Williams, \& Sparling, 1972). In one study, for example, people who had been led to believe that their negligence had ruined the study in which they were participating - and who consequently felt guilty about their behaviorlater contributed more to a charity (Regan, 1971).

The fact that there seem to be multiple ways to balance the scales raises a number of questions. One concerns the interchangeability of the various means by which a person can deal with self-recrimination. Does doing a good deed for someone render it unnecessary to self-punish because the scales are already balanced? For that matter, does washing one's hands diminish the impulse to harm oneself because one's sin has been washed away? Because each of these actions is aimed at achieving the same goal of relief from self-recrimination, it is possible that they could serve as substitutes for one another. There is some evidence for the interchangeability of these actions already-Zhong and Liljenquist (2006) showed that that washing one's hands after recalling a bad deed diminished participants' willingness to help a needy student. If the different ways of dampening self-recrimination all work to some degree, are some means preferred over others? It certainly seems easier - and therefore presumably more welcome-to wash one's hands than to, say, cut one's hands. If given the option to choose a method to balance the scales after a misdeed, people may therefore try the least painful or troublesome method first, and save the more troublesome methods for when the former fail. Alternatively, it may be that people employ a strategy of matching the severity of the remedy to the severity of their misdeed-washing their hands of minor transgressions, while physically harming themselves as punishment for their more significant failings.

Finally, it is unclear whether self-punishment would occur if the possibility of helping the victim of a misdeed were available. Would people still self-inflict punishment even if they were able to help or make amends? Or might people prefer a method that allowed them to simultaneously help another person while also self-inflicting pain over a method that was limited to only selfinflicted pain?

Although there are many questions remaining, one thing seems clear: With so many promising avenues for research, the future of self-punishment looks surprisingly bright.

\section{References}

Bastian, B., Jetten, J., \& Fasoli, F. (2011). Cleansing the soul by hurting the flesh: The guilt-reducing effect of pain. Psychological Science, 22, 334-335. doi:10.1177/0956797610397058

Baumeister, R. F., Stillwell, A. M., \& Heatherton, T. F. (1994). Guilt: An interpersonal approach. Psychological Bulletin, 115, 243-267. doi: 10.1037/0033-2909.115.2.243

Bloom, P. (2010). How pleasure works: The new science of why we like what we like. New York, NY: W. W. Norton \& Co.

Carlsmith, J. M., \& Gross, A. E. (1969). Some effects of guilt on compliance. Journal of Personality and Social Psychology, 11, 232-239. doi: 10.1037/h0027039

Darlington, R. B., \& Macker, C. E. (1966). Displacement of guilt-produced altruistic behavior. Journal of Personality and Social Psychology, 4, 442-443. doi:10.1037/h0023743

Freud, S. (1924/1953). The economic problem of masochism. In J. Strachey (Ed.), The standard edition of the complete psychological works of Sigmund Freud (Vol. 19, pp. 155-170). London, UK: Hogarth Press.

Houellebecq, M. (2011). The map and the territory (G. Bowd, Trans.). New York, NY: Random House.

Leff, G. (1999). Heresy in the later Middle Ages: The relation of heterodoxy to dissent, c. 1250-c. 1450. Manchester, UK: Manchester University Press.

Nelissen, R. M. A. (2012). Guilt induced self-punishment as a sign of remorse. Social Psychological \& Personality Science, 3, 139-144. doi: $10.1177 / 1948550611411520$

Nelissen, R. M. A., \& Zeelenberg, M. (2009). When guilt evokes selfpunishment: Evidence for the existence of a Dobby effect. Emotion, 9, 118-122. doi:10.1037/a0014540

Nisbett, R. E., \& Wilson, T. D. (1977). Telling more than we can know: Verbal reports on mental processes. Psychological Review, 84, 231-259. doi:10.1037/0033-295X.84.3.231

Nock, M. K., \& Prinstein, M. J. (2004). A functional approach to the assessment of self-mutilative behavior. Journal of Consulting and Clinical Psychology, 72, 885-890. doi:10.1037/0022-006X.72.5.885 
Nock, M. K., \& Prinstein, M. J. (2005). Contextual features and behavioral functions of self-mutilation among adolescents. Journal of Abnormal Psychology, 114, 140-146. doi:10.1037/0021-843X.114.1.140

Nock, M. K., Prinstein, M. J., \& Sterba, S. K. (2009). Revealing the form and function of self-injurious thoughts and behaviors: A real-time ecological assessment study among adolescents and young adults. Journal of Abnormal Psychology, 118, 816-827. doi:10.1037/a0016948

Nussbaum, M. C. (1993). Equity and mercy. Philosophy \& Public Affairs, $22,83-125$

O'Keefe, D. J., \& Figge, M. (1997). A guilt-based explanation of the door-in-the-face influence strategy. Human Communication Research, 24, 64-81. doi:10.1111/j.1468-2958.1997.tb00587.x

Regan, D. T., Williams, M., \& Sparling, S. (1972). Voluntary expiation of guilt: A field experiment. Journal of Personality and Social Psychology, 24, 42-45. doi:10.1037/h0033553

Regan, J. W. (1971). Guilt, perceived injustice, and altruistic behavior. Journal of Personality and Social Psychology, 18, 124-132. doi: $10.1037 / \mathrm{h} 0030712$
Schnall, S., Haidt, J., Clore, G. L., \& Jordan, A. (2008). Disgust as embodied moral judgment. Personality and Social Psychology Bulletin, 34, 1096-1109. doi:10.1177/0146167208317771

Tangney, J. P., \& Dearing, R. L. (2002). Shame and guilt. New York, NY: The Guilford Press.

Watson, D., Clark, L. A., \& Tellegen, A. (1988). Development and validation of brief measures of positive and negative affect: The PANAS scales. Journal of Personality and Social Psychology, 54, 1063-1070. doi:10.1037/0022-3514.54.6.1063

Zhong, C. B., \& Liljenquist, K. (2006). Washing away your sins: Threatened morality and physical cleansing. Science, 313, 1451-1452. doi: $10.1126 /$ science. 1130726

Received May 29, 2012

Revision received July 8, 2012

Accepted July 9, 2012 